\title{
Parkinson's Disease, the Dopaminergic Neuron and Gammahydroxybutyrate
}

\author{
Mortimer Mamelak (iD
}

Received: November 18, 2017 / Published online: January 24, 2018

(C) The Author(s) 2018. This article is an open access publication

\section{ABSTRACT}

The high energy demands of the substantia nigra pars compacta dopaminergic (DASNc) neurons render these neurons vulnerable to degeneration. These energy demands are a function of their long and extensively arborized axons and very large number of transmitter release sites, and are further augmented by their natural pacemaking activity. Pacemaking is driven by the rhythmic entry of $\mathrm{Ca}^{2+}$ into the cell and, while the entry of $\mathrm{Ca}^{2+}$ into the neuron stimulates energy (ATP) production, the extrusion of $\mathrm{Ca}^{2+}$ conversely saps the energy that is generated. DASNc neurons are said to be operating at a delicate equilibrium where any further stress or environmental demand may lead to their decompensation and degeneration. In experimental models of Parkinson's disease, reducing the energy requirements of these neurons by trimming the size of the neuronal arbor or by impeding the entry of $\mathrm{Ca}^{2+}$ into the cell has been shown to be protective. Increasing the energy supply to these neurons with D-betahydroxybutyrate has also been shown to be

Enhanced content To view enhanced content for this article go to http://www.medengine.com/Redeem/612D F0600A8FB647.

M. Mamelak ( $\square)$

Department of Psychiatry, Baycrest Hospital

University of Toronto, Toronto, Canada

e-mail:m.mamelak@utoronto.ca protective. The use of gammahydroxybutyrate holds great promise as a neuroprotective in Parkinson's disease because it can act as an energy source for the cell while simultaneously arresting its pacemaking activity and the entry of $\mathrm{Ca}^{2+}$ into the cell. Short clinical trials of gammahydroxybutyrate in Parkinson's disease have already demonstrated its immediate capacity to significantly reduce daytime fatigue and sleepiness and to improve sleep at night.

Keywords: Calcium channels; Dopaminergic neurons; Ketone bodies; Parkinson's disease; Sodium oxybate

\section{PLAIN LANGUAGE SUMMARY}

The degeneration of the dopaminergic neurons in the brain is thought to play a key role in the development of Parkinson's disease. These neurons are vulnerable to degeneration because of their extensive branching and the large amounts of energy required to send nerve signals along this extensive network. Dopaminergic neurons are also pacemaking neurons. This means that they are constantly rhythmically discharging and therefore require a great deal of energy to recharge. Neurons degenerate when they run out of energy. Studies are now underway to protect these neurons and prevent the development of Parkinson's disease by reducing 
their energy requirements. It may be possible to dramatically reduce the energy requirements of these neurons and to prolong their longevity with the nightly use of gammahydroxybutyrate. This agent turns off pacemaking. A brief clinical trial of gammahydroxybutyrate in patients with Parkinson's disease has already demonstrated clinical benefits.

\section{COMMENTARY}

The high energy demands of the dopaminergic neurons which project from the substantia nigra pars compacta (DASNc) appear to render these neurons vulnerable to degeneration $[1,2]$. These demands are a function of their anatomical structure and their spontaneous tonic activity. DASNc neurons have long and profusely branched axons and are relatively unmyelinated at least after they arborize and each one gives rise to an enormous number of synapses targeting and coordinating the activity of spatially distributed networks in the striatum $[1,2]$. Each of the 382,000 DASNc neurons in a single hemisphere of the human brain is estimated to have an average total length of about $4.5 \mathrm{~m}$ and to give rise to between 1 and 2.4 million synapses [1]. Action potential propagation along this vast and complex unmyelinated arbor greatly raises the energy requirements of these neurons. This energy cost is not directly proportional to the surface area or to the length of the axonal arbor but rather increases directly with the number of levels of branches the axon has and grows as a power law of the size and complexity, i.e., the surface area and number of branch points of the axon [1,3] Cellular trafficking along the microtubules of these long axons places an additional demand on the motor proteins, kinesin and dynein, powered by ATP [4].

DASNc neurons are autonomous pacemakers with broad action potentials which spike at $2-10 \mathrm{~Hz}$ in the absence of any excitatory input. Early in life, pacemaking relies on $\mathrm{Na}^{+}$channels acting in partnership with hyperpolarizationactivated cyclic nucleotide gated cation ( $\mathrm{HCN})$ channels. With age, pacemaking is increasingly driven by voltage-dependent L-type, i.e., low threshold, calcium channels inserted into the plasma membrane [5]. These channels have a distinctive pore-forming subunit $\left(\mathrm{Ca}_{\mathrm{v}} 1.3\right)$ which allows them to open at relatively negative membrane potentials which are lower than the threshold for firing action potentials [6]. The electrical current entering the cell through these channels then depolarizes the membrane to the threshold for action potentials. $\mathrm{Ca}_{\mathrm{v}} 1.3$ channels operate in tandem with $\mathrm{Na}^{+}$and $\mathrm{HCN}$ channels. Pacemaking activity in DASNc neurons can be maintained by ion flow through these $\mathrm{Na}^{+}$and $\mathrm{HCN}$ channels when $\mathrm{Ca}^{2+}$ entry is antagonized [5]. The calcium current underlying pacemaking is not large but it is almost continuously maintained and occurs throughout the network of branching dendrites that constitute most of the neurons' surface area [7]. This tonic activity and the coupled entry of $\mathrm{Ca}^{2+}$ into the neurons leads to high intracellular $\mathrm{Ca}^{2+}$ concentrations, particularly in the dendrites, but maintains the sustained release of dopamine required for the optimal functioning of the striatum $[5,8,9]$. Dopamine is also concurrently released from somatodendritic sites in the midbrain [10]. The activity of DASNc neurons can be inhibited by dopamine itself acting on D2 autoreceptors located presynaptically and on somatodendritic structures. Activation of D2 autoreceptors opens inwardly rectifying $\mathrm{K}^{+}$channels that hyperpolarize the neuron and inhibit its electrical activity [10].

For $\mathrm{Na}^{+}$and $\mathrm{K}^{+}$, the concentration differences maintained across the plasma membrane are similar and range between 10- and 30-fold. This must be compared to the 20,000-fold difference in the concentration of $\mathrm{Ca}^{2+}$ across the plasma membrane of about $100 \mathrm{nM}$ in the intracellular space and $2 \mathrm{mM}$ in the extracellular space. Following an action potential, a single molecule of ATP is required by $\mathrm{Na}^{+}, \mathrm{K}^{+}$-ATPase to pump out $3 \mathrm{Na}^{+}$ions in exchange for $2 \mathrm{~K}^{+}$ ions. In contrast, plasma membrane $\mathrm{Ca}^{2+}$ ATPase consumes a single molecule of ATP to extrude a single ion of $\mathrm{Ca}^{2+} \cdot \mathrm{Ca}^{2+}$ entry therefore raises the energy requirements of DASNc neurons. Once in the cell, $\mathrm{Ca}^{2+}$ activates $\mathrm{K}^{+}$ channels to help repolarize the membrane and prevent the generation of another spike [6]. However, the repolarization of L-type $\mathrm{Ca}^{2+}$ 
channels occurs slowly, and this, in turn, accounts for the broad form of the $\mathrm{Ca}^{2+}$ spikes in DASNc neurons, the increased entry of $\mathrm{Ca}^{2+}$ into the cell and the relatively high intracellular $\mathrm{Ca}^{2+}$ levels [11].

DASNc neurons are vulnerable to these high intracellular $\mathrm{Ca}^{2+}$ levels because of their poor intrinsic $\mathrm{Ca}^{2+}$ buffering capacity. These neurons contain relatively low levels of the $\mathrm{Ca}^{2+}$ binding proteins, calbindin and calretinin, which protect other dopaminergic neurons in the brain [12]. For example, dopaminergic neurons emanating from the ventral tegmental area (VTA) are much less vulnerable to degeneration in Parkinson's disease (PD) than DASNc neurons even though they are also autonomous pacemakers with broad spikes and even though they appear to have a higher basal firing rate than DASNc neurons [17]. Their reduced risk of degenerating may in part be attributed to an order of magnitude fewer synapses and a much smaller axonal arbor and, as discussed earlier, a corresponding reduced demand for energy [3]. However, in addition, VTA neurons have a lower density of L-type $\mathrm{Ca}^{2+}$ channels and a strong intrinsic calbindin $\mathrm{Ca}^{2+}$ buffering capacity [13]. By binding $\mathrm{Ca}^{2+}$, these $\mathrm{Ca}^{2+}$ binding buffers keep the $\mathrm{Ca}^{2+}$ away from signaling proteins and key organelles [6]. Intracellular $\mathrm{Ca}^{2+}$ can be toxic by directly or indirectly activating proteases such as calpains and calpases that degrade cytoskeletal proteins, membrane receptors and metabolic enzymes among other key cellular components [12]. The actions of these proteases link the apoptotic and necrotic cell death pathways [14]. Thus, this threefold combination of broad spikes, $\mathrm{Ca}^{2+}$ oscillations and poor $\mathrm{Ca}^{2+}$ buffering capacity, but none of these features alone, renders these neurons particularly vulnerable to multiple stressors such as aging, genetic factors and environmental toxins, and thus to degeneration [2].

Calcium that is not rapidly extruded from the cell is pumped into the endoplasmic reticulum (ER) from where it can flow into the mitochondria which communicate with the ER through mitochondria-associated membranes (MAM). Mitochondria densely populate DASNc neurons and collaborate with the ER to control intracellular $\mathrm{Ca}^{2+}$ homeostasis. $\mathrm{Ca}^{2+}$ influx into the mitochondria accelerates the citric acid cycle and increases the respiratory capacity of the cell [15]. Low micromolar concentrations of $\mathrm{Ca}^{2+}$ stimulate the activities of pyruvate dehydrogenase, isocitrate dehydrogenase- 3 and 2-oxoglutarate D-hydrogenase to increase the production of the reducing equivalents required for oxidative phosphorylation. In doing so, the influx of $\mathrm{Ca}^{2+}$ increases the production of ATP [16]. The very high density of mitochondria in DASNc neurons is likely needed to meet the energy demands of neurotransmission along the uniquely vast and complex axonal arbor of DASNc neurons [17]. These mitochondria are thought to be operating at maximal capacity and to have little energy reserve [17]. However, while $\mathrm{Ca}^{2+}$ may fire up the engines of energy production, the high rate of electron flux along the respiratory chain is accompanied by a high rate of free radical (ROS) formation. DASNC neurons have chronically high levels of ROS production which react with key elements of the cell and specifically with mitochondria to impair their function. This stressed metabolic environment makes it difficult for these neurons to cope with any additional stressors, be they genetic, environmental or aging. In cell culture studies, reducing the size of the neuronal arbor reduces basal levels of oxidative phosphorylation and oxidative stress and improves the survival of these neurons in response to environmental toxins [17].

Toxins such as 1-methyl-4-phenyl-1,2,3,6tetrahydropyridine (MPTP), the insecticide rotenone and 6-hydroxydopamine have all been employed to damage DASNc neurons and to create experimental models of PD in rodents and primates [5, 18-20]. MPTP and rotenone both act, at least in part, by interfering with the flow of electrons through complex I (NADHubiquinone oxidoreductase) of the respiratory chain and by generating ROS. The action mechanism of 6-hydroxydopamine is less clear, but it also appears to damage dopaminergic neurons by generating ROS either through autooxidation or by interfering with the operations of the respiratory chain [21]. Interfering with the flow of electrons through complex I of the respiratory chain is thought to model the 
depression in complex I activity found naturally in the DASNc neurons and other tissues in PD [22]. In all three cases, the damaging effect of low doses of these toxins on DASNc neurons can be attenuated by preventing the entry of $\mathrm{Ca}^{2+}$ into the cell through L-type $\mathrm{Ca}_{\mathrm{V}} 1.3$ channels with the use of dihydropyridine (DHP) calcium channel blockers such as nifedipine or isradipine. DHPs do not block the $\mathrm{Ca}^{2+}$ channel pores but act rather by impeding their activation [13]. Preliminary work reveals that genetic deletion of L-type Cav1.3 channels can also provide DASNc neurons with much the same protection against MPTP as isradipine [5]. The significance of these tissue protective effects is underscored by the conclusions of a recent retrospective epidemiological study which found that the risk of clinical PD was reduced by $27 \%$ among users of dihydropyridine calcium channel blockers, although it should be noted that the risk of PD was also reduced by $30 \%$ among users of non-dihydropyridine calcium channel blockers [23]. And, indeed, another retrospective epidemiological study found no specific beneficial effect on the progress of PD when the use of brain-penetrating DHPs was compared with non-brain-penetrating DHPs [24]. Thus, while in vitro models suggest that DHPs are neuroprotective, their place in the management of PD remains uncertain and will hopefully be clarified in a large prospective 5-year controlled clinical trial now underway on the prevention of PD with isradipine, the DHP with the highest affinity for L-type $\mathrm{Ca}^{2+}$ channels $[18$, clinicaltrials.gov].

While trimming the extensive arbor of DASNc neurons or antagonizing the entry of calcium into these cells may protect them by reducing the rate of energy production and concomitantly reducing the rate of ROS production, it may be possible to avert the energy crisis these cells face by augmenting their rate of energy production $[1,3]$. Infusion of the ketone body, D- $\beta$-hydroxybutyrate (D- $\beta \mathrm{HB})$, has been shown to mitigate the degenerative effects and motor deficits induced by MPTP in mice, while at the same time improve mitochondrial respiration and ATP formation [22]. In isolated mitochondria, D- $\beta \mathrm{HB}$ improves oxygen consumption in the presence of complex I inhibitors, MPTP and rotenone. D- $\beta \mathrm{HB}$ is metabolized to acetoacetate and to acetyl-CoA. A rise in the levels of acetyl-CoA increases the turnover of tricyclic acid intermediates and raises mitochondrial succinate levels. Succinate can bypass the block at complex I and support mitochondrial respiration by entering the respiratory chain at complex II (succinate-ubiquinone oxidoreductase). The increase in mitochondrial respiration with $\mathrm{D}-\beta \mathrm{HB}$ and its protective effect on DASNc neurons are lost when complex II is inhibited [22].

However, it may be possible to go one step further and to protect DASNc neurons both by reducing the influx of $\mathrm{Ca}^{2+}$ and by increasing the supply of energy. Gammahydroxybutyrate (GHB), a GABA metabolite found in all cells, plant and animal, can completely suppress pacemaking activity in DASNc neurons in rats even in low subanaesthetic doses. Cessation of impulse flow is accompanied by a marked increase in neuronal dopamine levels and tyrosine hydroxylase activity. A corresponding increase in dopamine levels and tyrosine hydroxylase activity is found in striatal slices when $\mathrm{Ca}^{2+}$ is removed from the medium [25-27]. A study on the effects of GHB on the dopamine neurons in slices of the rat ventral tegmental area found that perfusates containing GHB caused a concentration $\mathrm{K}^{+}$-dependent membrane hyperpolarization and eliminated $\mathrm{Ca}^{2+}$ spikes. Spontaneous firing of action potentials was completely blocked with $3 \mathrm{mM}$ GHB but the effects vanished within about $10 \mathrm{~min}$ after washout [28]. These actions of GHB are mediated by the actions of GHB on the $\mathrm{GABAB}$ receptor and are abolished by GABAB receptor antagonists [28, 29].

GHB can also serve as a source of energy for the brain and as an effective antioxidant. GHB enters the TCA in the form of succinate following its conversion to succinic semi-aldehyde and its oxidation to succinate. These steps also generate NADH and NADPH, two co-factors that play key roles in the neutralization of ROS $[30,31]$. GHB has been shown to have widespread tissue protective effects and to specifically protect the brain against ischemic or excitotoxic damage. It can maintain brain ATP levels in the face of hypoxia. Clinical studies 
demonstrate that it increases blood flow to the brain [32].

Pathological studies of the Parkinsonian brain have made it evident that degenerative changes are not limited to DASNc neurons but can also be identified in neurons in the dorsal motor nucleus of the vagus, in the locus coeruleus, in the raphe nuclei, in the tuberomamillary nucleus of the hypothalamus and in the basal forebrain, among others $[1,6]$. These neurons may be vulnerable because of the phenotypic features they have in common with DASNc neurons. For example, locus coeruleus neurons are autonomous pacemakers that utilize L-type $\mathrm{Ca}^{2+}$ channels [33]. GHB may be able to protect these neurons. Noradrenergic locus coeruleus neurons in rats are exquisitely sensitive to the depressant effects of GHB. Very low doses reduce the spontaneous firing rate and the evoked burst firing of these neurons by about $50 \%$ [34]. Cholinergic neurons, much like dopaminergic neurons, accumulate acetylcholine in response to a cessation of impulse flow [35]. GHB, administered to rats in the lactone form, increases acetylcholine levels in the striatum and hippocampus. This effect has been attributed to the inhibition of cholinergic neurotransmission by GHB. GHB produces a dosedependent reduction in extracellular acetylcholine levels in the hippocampus which can be monitored by microdialysis. GABAB receptor antagonists block this effect of GHB, again much like these antagonists block the accumulation of dopamine produced by GHB in dopaminergic neurons [36]. The actions of GHB on these diverse neuronal types require further study.

Short open label clinical trials of GHB in patients with PD have demonstrated that the drug is well tolerated and that it significantly reduced excessive daytime drowsiness and fatigue and improved the quality of sleep [37, 38]. Whether these immediate beneficial clinical effects are due to improved functioning of the dopaminergic neuron remains to be determined, but the clinical trials conducted to date suggest that GHB can be safely given to patients with PD to their advantage. Thus, the use of GHB has immediate and important clinical benefits that are not duplicated by $\mathrm{Ca}^{2+}$ channel blockers. There is also indirect evidence that the long-term use of GHB alone or in combination with D-BHB would have a neuroprotective effect, and that it may delay the onset of PD or slow its progress. According to the Xyrem ${ }^{\circledR}$ website, as of 2015 , GHB has been prescribed to more than 60,000 patients. It has been used nightly for many decades by patients with narcolepsy without major untoward effects. Embase and Medline databases have no case reports about the development of PD in these patients leading to the discontinuation of drug use. The Jazz Pharmaceutical Drug Safety and Pharmacovigilance Program does not identify PD as a safety signal for sodium oxybate $\left(\right.$ Xyrem $\left.^{\circledR}\right)$ (Jazz Pharmaceuticals-Medical Information Department). Formal epidemiological studies are required to determine the incidence and prevalence of PD in long-term users of GHB. The development of ketone esters of $\mathrm{D}-\beta \mathrm{HB}$ and slow-release GHB may greatly facilitate the clinical use of these agents [39, Flamel Technologies-website].

Funding. No funding or sponsorship was received for this study or publication of this article.

Authorship. The author declares that he is the sole author of this article. The author meets the International Committee of Medical Journal Editors criteria for authorship of this article, takes responsibility for the integrity of the work as a whole, and has given his approval for this version to be published.

Disclosures. Mortimer Mamelak has nothing to declare.

Compliance with Ethics Guidelines. This article is based on previously conducted studies and does not contain any studies with human participants or animals performed by the author.

Open Access. This article is distributed under the terms of the Creative Commons Attribution-NonCommercial 4.0 International License (http://creativecommons.org/licenses/ by-nc/4.0/), which permits any 
noncommercial use, distribution, and reproduction in any medium, provided you give appropriate credit to the original author(s) and the source, provide a link to the Creative Commons license, and indicate if changes were made.

\section{REFERENCES}

1. Bolam JP, Pissadaki EK. Living on the edge with too many mouths to feed: why dopamine neurons die. Mov Disord. 2012;27:1478-83.

2. Surmeier DJ, Obeso JA, Halliday GM. Selective neuronal vulnerability in Parkinson disease. Nat Rev Neurosci. 2017;18:101-13.

3. Pissadaki EK, Bolam JP. The energy cost of action potential prpogation in dopamine neurons:clues to susceptibility in Parkinson's disease. Front Comput Neurosci. 2013;7:13.

4. Hunn BH, Cragg SJ, Bolam JP, Spillantini MG, Wade-Martins R. Impaired intracellular trafficking defines early Parkinson's disease. Trends Neurosci. 2015;38:178-88.

5. Chan CS, Guzman JN, Ilijic E, Mercer JN, Rick C, Tkatch T, Meredith GE, Surmeier DJ. Rejuvenation' protects neurons in mouse models of Parkinson's disease. Nature. 2007;447:1081-6.

6. Surmeier DJ, Guzman JN, Sanchez J, Schumacker PT. Physiological phenotype and vulnerability in Parkinson's disease. Cold Spring Harb Perspect Med. 2012;2:a009290.

7. Bean BP. The action potential in mammalian central neurons. Nat Rev Neurosci. 2007;8:451-65.

8. Wilson CJ, Callaway JC. Coupled oscillator model of the dopaminergic neuron of the substantia nigra. J Neurophysiol. 2000;83:3084-100.

9. Guzman JN, Sanchez-Padilla J, Chan CS, Surmeier DJ. Robust pacemaking in substantia nigra dopaminergic neurons. J Neurosci. 2009;29:11011-9.

10. Duda J, Potschke C, Liss B. Converging roles of ion channels, calcium, metabolic stress, and activity pattern of substantia nigra dopaminergic neurons in health and Parkinson's disease. J Neurochem. 2016;139(Suppl 1):156-78.
11. Surmeier DJ, Schumacker PT. Calcium, bioenergetics, and neuronal vulnerability in Parkinson's disease. J Biol Chem. 2013;288:10736-41.

12. Mattson MP. Calcium and neurodegeneration. Aging Cell. 2007;6:337-50.

13. Surmeier DJ, Schumacker PT, Guzman JD, Ilijic E, Yang B, Zampese E. Calcium and Parkinson's disease. Biochem Biophys Res Commun. 2017;483:1013-9.

14. Harwood SM, Yaqoob MM, Allen DA. Caspase and calpain function in cell death: bridging the gap between apoptosis and necrosis. Ann Clin Biochem. 2005;42:415-31.

15. Denton RM, McCormack JG. The calcium sensitive dehydrogenases of vertebrate mitochondria. Cell Calcium. 1986;7:377-86.

16. Balaban RS. The role of $\mathrm{Ca}(2+)$ signaling in the coordination of mitochondrial ATP production with cardiac work. Biochim Biophys Acta. 2009;1787:1334-41.

17. Pacelli C, Giguere N, Bourque MJ, Levesque M, Slack RS, Trudeau LE. Elevated mitochondrial bioenergetics and axonal arborization size are key contributors to the vulnerability of dopamine neurons. Curr Biol. 2015;25:2349-60.

18. Ilijic E, Guzman JN, Surmeier DJ. The L-type channel antagonist isradipine is neuroprotective in a mouse model of Parkinson's disease. Neurobiol Dis. 2011;43:364-71.

19. Kupsch A, Gerlach M, Pupeter SC, Sautter J, Dirr A, Arnold G, Opitz W, Przuntek H, Riederer P, Oertel WH. Pretreatment with nimodipine prevents MPTP-induced neurotoxicity at the nigral, but not at the striatal level in mice. NeuroReport. $1995 ; 6: 621-5$.

20. Kupsch A, Sautter J, Schwarz J, Riederer P, Gerlach M, Oertel WH. 1-Methyl-4-phenyl-1,2,3,6-tetrahydropyridine-induced neurotoxicity in non-human primates is antagonized by pretreatment with nimodipine at the nigral, but not at the striatal level. Brain Res. 1996;741:185-96.

21. Bove J, Prou D, Perier C, Przedborski S. Toxin-induced models of Parkinson's disease. NeuroRx. 2005;2:484-94.

22. Tieu K, Perier C, Caspersen C, Teismann P, Wu DC, Yan SD, Naini A, Vila M, Jackson-Lewis V, Ramasamy R, Przedborski S. D-Beta-hydroxybutyrate rescues mitochondrial respiration and mitigates features of Parkinson disease. J Clin Invest. 2003;112:892-901. 
23. Lang Y, Gong D, Fan Y. Calcium channel blocker use and risk of Parkinson's disease: a meta-analysis. Pharmacoepidemiol Drug Saf. 2015;24:559-66.

24. Marras C, Gruneir A, Rochon P, Wang X, Anderson G, Brotchie J, Bell CM, Fox S, Austin PC. Dihydropyridine calcium channel blockers and the progression of parkinsonism. Ann Neurol. 2012;71:362-9.

25. Walters JR, Roth RH. Dopaminergic neurons: druginduced antagonism of the increase in tyrosine hydroxylase activity produced by cessation of impulse flow. J Pharmacol Exp Ther. 1974;191:82-91.

26. Morgenroth VH III, Walters JR, Roth RH. Dopaminergic neurons-alteration in the kinetic properties of tyrosine hydroxylase after cessation of impulse flow. Biochem Pharmacol. 1976;25:655-61.

27. Roth RH, Doherty JD, Walters JR. Gamma-hydroxybutyrate: a role in the regulation of central dopaminergic neurons? Brain Res. 1980;189:556-60.

28. Madden TE, Johnson SW. Gamma-hydroxybutyrate is a $\mathrm{GABAB}$ receptor agonist that increases a potassium conductance in rat ventral tegmental dopamine neurons. J Pharmacol Exp Ther. 1998;287:261-5.

29. Erhardt S, Andersson B, Nissbrandt H, Engberg G. Inhibition of firing rate and changes in the firing pattern of nigral dopamine neurons by gammahydroxybutyric acid (GHBA) are specifically induced by activation of GABA(B) receptors. Naunyn Schmiedebergs Arch Pharmacol. 1998;357:611-9.

30. Mamelak M. Energy and the Alzheimer brain. Neurosci Biobehav Rev. 2017;75:297-313.

31. Mamelak M. Sporadic Alzheimer's disease: the starving brain. J Alzheimers Dis. 2012;31:459-74.

32. Bosch OS, Esposito F, Havranek MM, Dornbierer D, Van Rotz R, Stampfli P, Quednow BB, Seifritz E.
Gammahydroxybutyrate increases resting state limbic perfusion and body and emotion awareness. Neuropsychpharmacol. 2017;42:2141-51.

33. Williams JT, North RA, Shefner SA, Nishi S, Egan TM. Membrane properties of rat locus coeruleus neurones. Neuroscience. 1984;13:137-56.

34. Szabo ST, Gold MS, Goldberger BA, Blier P. Effects of sustained gamma-hydroxybutyrate treatments on spontaneous and evoked firing activity of locus coeruleus norepinephrine neurons. Biol Psychiatry. 2004;55:934-9.

35. Sethy VH, Roth RH, Walters JR, Marini J, Van Woert $\mathrm{MH}$. Effect of anesthetic doses of gamma-hydroxybutyrate on the acetylcholine content of rat brain. Naunyn Schmiedebergs Arch Pharmacol. 1976;295:9-14.

36. Nava F, Carta G, Bortolato M, Gessa GL. Gammahydroxybutyric acid and baclofen decrease extracellular acetylcholine levels in the hippocampus via GABA(B) receptors. Eur J Pharmacol. 2001;430:261-3.

37. Ondo WG, Perkins T, Swick T, Hull KL Jr, Jimenez JE, Garris TS, Pardi D. Sodium oxybate for excessive daytime sleepiness in Parkinson disease: an openlabel polysomnographic study. Arch Neurol. 2008;65:1337-40.

38. Buchele F, Hackius M, Schregglmann SR, Omior W, Werth E, Marie A, Imbach LL, Hagele-Link S, Waldvogel D, Baumann CR. Sodium oxybate for excessive daytime sleepiness and sleep disturbance in Parkinson disease. JAMA Neurol. 2017. https:// doi.org/10.1001/jamaneurol.2017.3171 (published online November 6,2017 ).

39. Newport MT, VanItallie TB, Kashiwaya Y, King MT, Veech RL. A new way to produce hyperketonemia: use of ketone ester in a case of Alzheimer's disease. Alzhimers Dement. 2015;11:99-103. 